\title{
LA LESION
}

Manuel de la Puente y Lavalle

- Con motivo de una huelga de transportistas públicos, un chofer de taxi, abusando de la necesidad de un pasajero de trasladarse a otro lugar de la ciudad, le cobra una carrera a un precio cuatro veces superior al normal.

- El capitán de un barco, aprovechándose conscientemente de la necesidad de otro barco que ha quedado a la deriva, pacta con el capitán de éste una cantidad exorbitante por efectuar el remolque a puerto.

- Conociendo la necesidad de dinero en que se encuentra una persona, un coleccionista de antigüedades conviene con ella en adquirir un cuadro muy valioso por un precio vil.

- Una empresa suministradora de servicios, abusando de su situación de monopolio, fija a los usuarios del servicio tarifas que no guardan relación con el servicio prestado, las cuales son aceptadas por los usuarios debido a la necesidad apremiante que tienen de los servicios.

$i$ Debe respetarse la santidad de estos contratos o, por el contrario, debe el Derecho proporcionar remedios a fin de alcanzar la rescisión de los mismos o su modificación? 
Esta es la pregunta que desde hace centenas de años se formulan, con evidente preocupación, los juristas.

La respuesta es difícil, casi diria dolorosa para un amante del Derecho, porque el problema de la lesión tiene sus raices en el viejo conflicto, que en nuestros tiempos se presentan con tan angustiosa frecuencia, entre la seguridad juridica y la justicia.

Conviene echar una mirada atrás para conocer cual ha sido la reacción del Derecho ante la pugna de estos principios que se presenta cuando existe una desproporción inicial evidente entre las prestaciones de un contrato oneroso. Esta fugaz reseña histórica no tiene otra finalidad que la de conocer cual es el marco jurídico dentro del cual se aprecia, en cada época, la admisión o el rechazo de la acción por lesión.

Sin embargo, antes de hacerlo conviene precisar, para captar mejor el desarrollo histórico de la lesión, que existen dos criterios para encontrar su justificación. Un primer criterio, llamado objetivo, estima que en todo contrato a titulo oneroso debe existir un equilibrio entre la prestación y la contraprestación, y que si ese equilibrio no se respeta, el contrato no puede surtir efectos. Otro criterio, llamado subjetivo, considera que la lesión se produce por una debilidad del consentimiento por parte de la victima de la lesión, que la lleva a aceptar un contrato que le es manifiestamente perjudicial.

Ignorada en Grecia, la lesión cobra cuerpo en el Derecho romano con el Corpus Iuris Civiles de JUSTINIANO, que concede la acción rescisoria al vendedor cuando el precio pagado por el bien es menor que la mitad de su precio verdadero, o sea aceptando el criterio objetivo. Se justifica esta solución en el razonamiento de que si se vende por menos precio una cosa de precio mayor, es humano que restituyéndose el precio al comprador, se recobre la cosa vendida, mediante la autoridad del juez.

En la Edad Media, por inspiración de la doctrina cristiana que impone el deber de caridad y amor al prójimo y debido a la decisiva influencia de SANTO TOMAS, se desarrolla la "teoría de justo precio", que prohibia obtener de un contrato un provecho 
excesivo con perjuicio del otro contratante, lo que llevó a admitir la lesión en todos los contratos onerosos, inclusive los aleatorios.

El Código civil francés de 1804, fruto del liberalismo que surge con la Revolución Francesa, busca por todos los medios de robustecer la libertad contractual y consagra la fórmula de que las convenciones tienen fuerza de ley entre aquellos que las han hecho (artículo 1.134). Dentro de esta concepción, se aceptó como principio general que la lesión no vicia las convenciones sino en ciertos contratos o con relación a ciertas personas (artículo 1.118). Llegado el momento de tratar el título de la venta, se puso a debate la fórmula del proyecto presentado por la Comisión de Gobierno en 1800, que aceptada la rescisión del contrato por lesión enorme. PORTALIS y CAMBACERES de un lado y BERLIER y REGNAUD del otro, defendieron y atacaron, respectivamente, con gran denuedo la institución de la lesión en la compraventa. Se reconoce que fue decisiva la intervención de NAPOLEON, entonces Primer Cónsul, quien inclinó la balanza en el sentido de admitir la rescisión por lesión con carácter objetivo únicamente en materia de enajenación de inmuebles y sólo en favor del vendedor.

Dicen los MAZEAUD que más bien que hacer que reine la justicia en los contratos, los redactores del Código civil francés quisieron garantizar la seguridad juridica.

La influencia del Código NAPOLEON en las codificaciones europeas que le siguieron fue determinante. Los Códigos civiles de Bélgica, Luxemburgo y Mónaco copiaron fielmente el modelo francés. En América Latina, el Código civil chileno, y los de El Salvador, Colombia y Nicaragua que lo siguen muy de cer$\mathrm{ca}$, admiten la lesión enorme con carácter objetivo sólo en la compraventa y a favor tanto del vendedor como del comprador.

Debe advertirse, para comprender cabalmente la evolución de la lesión, que todos estos Códigos entraron en vigencia en el siglo XIX, cuando el liberalismo campeaba por sus respetos y la santidad de los contratos constituia un dogma cientifico. 
Es el Código civil alemán de 1900 el primer cuerpo legal que, aunque veladamente, incorpora la lesión a todos los contratos y abandona el criterio objetivo de la lesión enorme para reemplazarlo por una concepción subjetiva, que pone énfasis en la explotación por uno de los contratantes de la necesidad, ligereza e inexperiencia del otro.

El camino abierto por el Código civil alemán fue rápidamente seguido por el Código de las obligaciones suizo de 1911, que en su articulo 21 dispone que un contrato en el cual hay desproporción evidente entre la prestación prometida por una de las partes y la contraprestación de la otra, puede rescindirse a pedido de la parte lesionada, si la lesión ha sido determinada por la explotación de su penuria, ligereza o inexperiencia.

Es de particular interés poner de manifiesto cuales fueron las razones que determinaron esta nueva orientación de los Códigos de Alemania y Suiza, admirablemente expuesta por ROSSEL (*):

"A las viejas teorias individualistas, que encontraban como "el mejor el más libre de los mundos, nosotros les repro“chamos que sacrificaban el pobre al rico, el débil al fuerte, "y las hemos sustituido por una doctrina de acción colectiva "y solidaria.

"Los partidarios del laiser faite representan hoy un pasado "definitivamente superado... Lo que se puede y debe exigir "al derecho, especialmente al derecho civil, es que no man"tenga una fijeza injustificable en medio de un mundo que “cambia sin cesar, y que sea la expresión más completa po"sible de los deberes que los miembros de una sociedad tienen "unos respecto de los otros".

Como dice MOISSET DE ESPANES (**), se ha dado un giro en redondo.

(*) Cita de Luis MOISSET DE ESPANES, La lesión en los actos jurídicos, Córdoba, 1979, pág. 103.

(**) Luis MOISSET DE ESPANES, op. cit., pág. 103. 
La orientación de los Códigos alemán y suizo influyó nota blemente en muchos Códigos europeos del siglo XX, tales como los de Austria, Suecia, Noruega, Dinamarca, Finlandia, Polonia e Italia.

En América Latina, fue el Código civil mexicano de 1928 el primero que recogió la fórmula alemana disponiendo que la acción por lesión es procedente en todos los contratos en que uno, explotando la suma ignorancia, notoria inexperiencia o extrema miseria de otro, obtiene un lucro excesivo que sea evidentemente desproporcionado a lo que él por su parte se obliga.

Para calar la real importancia de este cambio con relación al antiguo Código civil mexicano de 1884, que seguía fielmente el enfoque francés de la lesión objetiva y circunscrita a la compraventa, conviene conocer el espíritu que inspiró el nuevo Código civil mexicano, que resulta con singular claridad de los Motivos de dicho Código:

"Nuestro actual Código civil, producto de las necesidades “económicas y jurídicas de otras épocas; elaborado cuando "dominaba en el campo económico la pequeña industria y en "el orden jurídico un exagerado individualismo, se ha vuelto "incapaz de regir las nuevas necesidades sentidas en las re"laciones que, aunque de carácter privado, se hallan fuerte"mente influenciadas por las diarias conquistas de la gran “industria y por los progresivos triunfos del principio de la "solidaridad.

"Para transformar un Código civil en que predomina el cri"terio individualista, en un código privado social, es preciso "reformarlo substancialmente, derogando todo cuanto favo" "rece exclusivamente el interés particular con perjuicio de la "colectividad, e introduciendo nuevas disposiciones que se ar "monicen con el concepto de solidaridad".

$Y$ más adelante, refiriéndose a la necesidad de la intervención del Estado en la contratación, que es el campo donde funciona la lesión, los mismos Motivos dicen: 
"La necesidad de cuidar de la mejor distribución de la ri"queza; la protección que merecen los débiles y los ignorantes "en sus relaciones con los fuertes y los ilustrados; ... han "hecho indispensables que el Estado intervenga para regular "las relaciones jurídico económicas, relegando a segundo tér"mino al no ha mucho triunfante principio de que la volun"tad de las partes es la suprema ley de los contratos'".

"La célebre fórmula de la escuela liberal, 'laissez faire, lai'ssez passer', es completamente inadecuada para resolver los "importantisimos y complejos problemas que a diario se pre"sentan en la vida contemporánea.

"La idea de solidaridad arraiga cada vez más en las con"ciencias y encausa por nuevos derroteros las ideas de liber"tad y de igualdad".

La evolución del Código civil argentino ha sido muy significativa. La versión original, que entró en vigencia en 1871, no consideraba la lesión como causa de rescisión de los contratos. Dalmacio VELEZ SARFIELD, redactor del Código, justifica esta posición diciendo en su conocida nota al artículo 943 lo siguiente:

"Dejariamos de ser responsables de nuestras acciones si la "ley nos permitiera enmendar todos nuestros errores, o to"das nuestras imprudencias. El consentimiento libre, prestado "sin dolo, error ni violencia y con las solemnidades reque"ridas por las leyes, debe hacer irrevocables los contratos".

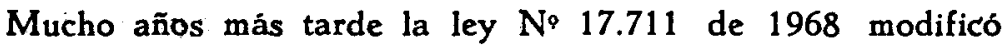
el artículo 954 del Código civil argentino, que señalaba que son nulos los actos practicados con los vicios de error, de dolo, de simulación o fraude, en el sentido de declarar anulables tales actos, agregando varios párrafos a dicho artículo, entre los cuales tiene particular importancia el segundo, que dice que también podrá demandarse la nulidad o la modificación de los actos juridicos cuando una de las partes explotando la necesidad, ligerez o inexperiencia de la otra, obtuviera por medio de ellos una ventaja patrimonial evidentemente desproporcionada y sin justificación. 
Puede observarse que, con pequeños cambios de redacción. se adopta la fórmula del artículo 21 del Código de las Obligaciones suizo, o sea la lesión subjetiva aplicable a todos los contratos.

En la legislación brasilera el derrotero ha sido similar, aunque con caracteristicas propias. El Código civil de 1917 no acepta la lesión en hipótesis alguna, esto es ni siquiera limitada al contrato de compraventa, como lo hacen el Código francés y sus seguidores, y es ésta la situación legislativa actual. Sin embargo. existe en el Brasil un Proyecto de Código civil elaborado en 1975, sometido por el Poder Ejecutivo a la deliberación del Congreso Nacional ese mismo año, cuyo artículo 155 señala que ocurre lesión cuando una persona, oprimida por la necesidad, o por inexperiencia, se obliga a una prestación manıfiestante desproporcionada al valor de la prestación opuesta.

La Exposición de Motivos del Proyecto justifica la necesidad de actualizar el Código civil de 1917 no sólo en la premura de superar los presupuestos individualistas que condicionaron su elaboración, sino también para dotarlo de instituciones nuevas, reclamadas por la sociedad actual, en los dominios de las actividades empresariales y en los demás sectores de la vida privada.

Resultaría fuera del lugar alargar este análisis de la evolución del concepto de lesión en las codificaciones mundiales, que se ha centrado en las europeas y latinoamericanas por tener tanta influencia en el pensamiento juridico peruano, pero pienso que la reseña hecha es suficiente para apreciar que el tratamiento legislativo de la lesión está intimamente vinculado a la concepción del rol del Derecho en la vida social.

Aquellos ordenamientos juridicos que se inspiran en el principio liberal, que respetan en toda su extensión la obligatoriedad irrestricta del contrato, que, en suma, protegen celosamente la seguridad juridica, se inclinan fatalmente por excluir la lesión o limitarla en sentido objetivo a la compraventa. Por el contrario. aquellos otros que aceptan la tendencia socializadora del Derecho, que admiten el fenómeno que JOSSERAND denomina como 
el "dirigismo contractual", según el cual la estabilidad de los contratos no es ya un dogma absoluto, que, en fin, colocan el sentimiento de la justicia por encima de la seguridad del tráfico, consideran como elemento indispensable para realizar esta concepción la regulación de la lesión con criterio subjetivo, aplicable a todos los contratos y en favor de ambos contratantes.

Podemos personalmente inclinarnos por una $u$ otra posición porque, al fin $y$ al cabo, ambas son respetables. Podemos pensar que es deber ineludible del hombre guardar fielmente la palabra empeñada; podemos creer en la santidad del contrato como principio de observancia necesaria para regular las relaciones entre los hombres; podemos, por último, venerar la libertad como el más preciado de los derechos, Podemos, por el contrario, considerar que es deber ineludible del Derecho velar por la protección del débil frente al poderoso; podemos entender que el principio de solidaridad debe iluminar todas las relaciones contractuales; podemos, finalmente, colocar a la justicia por encima de toda otra consideración.

Pero la experiencia histórica nos demuestra que no podemos, o al menos que la realidad no lo admite, buscar la seguridad juridica por encima de todo y propiciar la lesión, o ser rendidos amantes de la justicia y proscribir la lesión subjetiva.

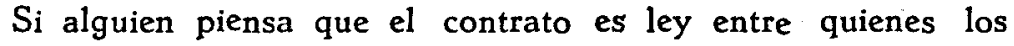
han celebrado, debe mirar con recelo una institución que no respete ese vinculo; si cree en la ley de la oferta y la demanda, debe desconfiar de un sistema que niega valor absoluto a esta ley. De otro lado, quien considera que el abuso de la necesidad de la otra parte resta valor al consentimiento contractual, ve con simpatia un arma que le permite dejar sin efecto la relación obligatoria asi contraida; si entiende que en todo contrato oneroso debe haber un equilibrio subjetivo de entre las prestaciones, le resulta útil una herramienta que le permite restablecer ese equilibrio cuando ha sido roto abusivamente.

Comprendo que la opción entre la seguridad juridica y la justicia es difícil, y sobre todo dolorosa. Muchos de nosotros nos hemos formado considerando a la seguridad juridica, que es hija 
de la libertad contractual, como un principio que nos permitia confiar en el Derecho como ley de la conducta de los hombres. Mientras la libertad y la justicia han ido de la mano, hemos respirado con alivio pues nuestra seguridad juridica estaba protegida. Pero el actual mundo del Derecho no nos permite continuar gozando de esa paz; enfrenta la seguridad juridica a la justicia y nos coloca despiadamente en la necesidad de elegir entre una y otra.

Personalmente, admiro la libertad. Pienso que hay que admitir el rol preponderante que juegan la voluntad y la libertad humanas para alcanzar una ley moral que proteja la dignidad y la grandeza del hombre.

Si embargo, todos somos conscientes que el abuso de la libertad; debido a que la igualdad y la libertad juridicas no concurren necesariamente al lado de la libertad e igualdad económicas, puede llegar a atentar contra la justicia de las transacciones. El sólo juego de la libertad puede hacer que un contratante poderoso imponga su voluntad al otro, o que éste, encontrándose en estado de necesidad, acepte una fórmula negocial no sólo desventajosa para sus intereses económicos, sino también muchas veces lesiva para su dignidad humana, lo que dará como resultado, en uno y otro caso, una situación injusta. $Y$ es aqui donde surge una consideración básica que debe iluminar todo el concepto de contrato y, consecuentemente, de la autonomia de la voluntad: la justicia.

Enmanuel GOUNOT (*) escribia ya en 1912: "En materia de contratos no hay más que un principio absoluto: la justicia. la libertad no es más que un medio hacia lo justo; ella se apoya sobre una presunción de justicia", y cita en su apoyo a IHERING, quien ha dicho: "La justicia está por encima de la libertad".

Me inclino, pues, rendidamente por la justicia. Pienso que si llega a ser indispensable sacrificar la seguridad jurídica que resulta de un contrato cuando la justicia contractual lo exige, debe

(*) Cita de André TUNC, Posibilidad de comparar el contrato entre sistemas jurídicos diferentes, México D. F., 1962, pág. 15 
hacerse el sacrificio. Coincido, por ello, con MANS (**) cuando declara que la justicia es un valor más alto que el orden y la seguridad.

Esta posición está implicitamente respaldada por el inciso 12) del artículo 2 de la Constitución Política del Perú, que concede a toda persona el derecho de contratar con fines licitos, pero permite que la ley regule el ejercicio de esta libertad para salvaguardar los principios de justicia y evitar el abuso del derecho. Es indudable que al amparo de esta norma, la seguridad juridica que resulta de la libertad contractual (libertad para determinar el contenido del contrato) puede ser sacrificada cuando se encuentra en pugna con la justicia.

A la luz de estas ideas, conviene examinar ya cual es el tratamiento legislativo que, al amparo de la disposición constitucional citada, debe dase a la acción por lesión. Caben dos grandes posibilidades, negarla o admitirla.

Negar la acción por lesión, que es la solución adoptada, entre las legislaciones que conozco, por los Códigos civiles de $\mathrm{Ho-}$ landa, Brasil, Honduras, Costa Rica, Uruguay y Haiti, significa respetar incondicionalmente los pactos contractuales y conceder a la regla francesa que otorga a los contratos fuerza de ley entre las partes que los celebran la más amplia acogida.

Esta orientación prescinde de la moralidad del contrato. Basada en la idea liberal individualista confiaba en que la ley de la oferta y la demanda, unida a la proclamada igualdad entre los hombres, lograria la justicia del contrato (*).

No cabe aceptar que aun cuando en un contrato oneroso exista una evidente desproporción entre la prestación y la contraprestación y que tal desproporción no haya sido querida por las partes sino impuesta por uno de los contratantes al otro abusando del estado de necesidad en que éste se encuentra, el Dere-

(*) Jaime M. MANS PUIGARNAU, Hacia una ciencia general del Derecho, Barcelona, 1970, pág. 59.

(3) José MOSSET ITURRASPE, Contratos, Buenos Aires, 1981, pág. 154. 
cho se ponga una venda y se abstenga de intervenir sólo porque el contrato es obligatorio entre las partes.

Han sido para mi muy inspiradoras las siguientes expresiones de BORDA $\left({ }^{*}\right)$ :

"Es indiscutible que no toda desigualdad autoriza a anular "o rescindir un contrato, pues la igualdad matemática es del "todo imposible. Pero cuando se hace visible que las obli"gaciones contraidas por una de las partes sólo lo han sido "en virtud de su ignorancia, su debilidad o su inexperiencia, "cuando es evidente que la otra parte se ha aprovechado de "estas circunstancias para sacarles provecho, el juez no pue"de convalidar tales convenciones que resultan repugnantes a "la moral y las buenas costumbres. Será necesario anularlas "o reducir las obligaciones a sus justos limites. Por que el "derecho presupone la justicia y no todo contrato, por el he"cho de serlo, es justo, como lo pretendian los voceros del "liberalismo. En el Derecho moderno, estos conceptos pue"den considerarse definitivamente triunfales".

En la medida que la acción por lesión esté encaminada a corregir la injusticia de que habla BORDA, considero que el Derecho debe ampararla y regularla. Si nos encontramos ante una situación en que el principio de la santidad del contrato, que vela por la seguridad juridica, se encuentra en pugna con la justicia que debe existir en toda relación juridica creada por un contrato, es preciso tener a la mano un remedio para hacer cesar esa pugna en beneficio de la justicia. Si este remedio es la acción por lesión, pues aceptémosla en buena hora.

Pero cabe preguntar, $i$ en todos los casos en que se admite la lesión, esto es tanto en su concepción objetiva como en la subjetiva, la acción por lesión alcanza esa finalidad..

Recordemos que según el concepto objetivo de lesión. ésta se produce cuando existe una desproporción evidente o notable entre las prestaciones, mientras que la concepción subjetiva atien-

(*) Guillermo A. BORDA, Manual de contratos, Buenos Aires, 1973, pág. 61. 
de principalmente al aprovechamiento por una parte de la necesidad o inexperiencia de la otra.

El ilustrado POTHIER decia que "la equidad debe reinar en las convenciones, de donde se sigue que en los contratos onerosos en los cuales uno de los contratantes da o hace algo para recibir alguna otra cosa como precio, la lesión que sufre uno de los contratantes, aun cuando el otro no haya recurrido a ningún artificio para engañarlo, basta por si misma para viciar los contratos. Porque consistiendo la equidad en materia de negocios en la igualdad, desde que se menoscabe esta igualdad y uno de los contratantes da más de lo que recibe, el contrato está viciado porque pesa contra la equidad que debe presidirlo".

Pienso que la sola desproporción entre las prestaciones, aun cuando ella exceda de los limites prudentes (lesión enorme), no justifica la acción por lesión. Cuantas veces las partes no sólo admiten sino que, es más, buscan el desequilibrio entre prestación y contraprestación por considerar que, no obstante tal desequilibrio, el contrato no les depara perjuicio. Tenemos el caso del contrato de donación, donde la desproporción llega a su limite máximo ya que la contraprestación no existe, que no puede considerarse un contrato lesivo pues ambas partes, donante y donatario, han querido que precisamente esa situación se produzca.

Comparto plenamente, pues, las criticas adversas que se formulan a la lesión objetiva, ya que como dicen BAUDRYLACANTINERIE y BARDE, el contrato es muchas veces un acto de previsión y lo que resulta hoy equitativo, mañana puede no serlo, por lo cual quizá sean estas circunstancias las previstas por las partes y las que han tenido en mira al contratar. Por otro lado, se dice $\left({ }^{*}\right)$ que el recurso de lesión trata de sustraer el precio de las cosas o servicios al natural influjo de las leyes de la oferta y la demanda, olvidancio que el valor de las cosas que se venden y de los servicios que se prestan es siempre el valor de "cambio", y no el intrinseco.

(*) Felipe SANCHEZ ROMAN, Estudios de Derecho civil, Madrid, 1899, Tomo IV, pág. 200. 
Estas consideraciones me llevan a pensar que la sola existencia de un desequilibrio desmesurado entre las ventajas del contrato no constituyen fundamento suficiente para justificar la acción por lesión.

En cambio, la lesión entendida en su concepción subjetiva ofrece un claro sustento juridico, inspirado en el principio de que los contratos deben celebrarse y ejecutarse de buena fe. Siempre que un contratante se encuentre en situación de necesidad y que sufra un perjuicio considerable por el abuso que hace la contraparte de esa situación, el Derecho debe ir en ayuda del contratante necesitado $y$, sobre todo, explotado, para hacer cesar los efectos del abuso, bien sea dejando sin efecto el contrato lesivo o bien, como medida sustitutoria, restableciendo el equilibrio de las prestaciones por la via de la revisión del contrato.

Debe observarse que la concepción subjetiva de la lesión no sólo exige la existencia de una situación de necesidad en el contratante lesionado sino también, y necesariamente, el abuso o explotación por parte del lesionante de esa necesidad del lesionado. La mala fe que caracteriza a la concepción subjetiva de la lesión no existiría si la lesión pudiera limitarse a la situación de necesidad del lesionado, prescindiéndose del abuso por el lesionante.

Como según el concepto generalmente aceptado la lesión sólo puede darse en los contratos onerosos, en los cuales la estimación de la equivalencia de las prestaciones obedece a un criterio subjetivo, y como, por otro lado, se requiere que el perjuicio sufrido por una de las partes tenga su razón de ser en la falta de equivalencia de las prestaciones existente en el momento de celebrarse el contrato, por lo cual es un perjuicio personal, pareceria que la solución correcta seria encontrar el fundamento de la acción por lesión en la existencia de un vicio de la voluntad que determina que la parte lesionada esté dispuesta a celebrar un contrato que debe set oneroso no obstante no serlo, en la realidad.

Esta fue la posición de Manuel Augusto OLAECHEA en el seno de la Comisión Revisora del Proyecto de Código civil, 
donde sostuvo que la lesión debe ser considerada como un vicio del consentimiento, porque en unos casos se puede clasificar en el error, en otros en la violencia, en otros en el dolo, por lo cual la lesión no constituye una categoria juridica especifica y propia.

Sin embargo, esta solución no debe ser aceptada en toda su amplitud. Los vicios de la voluntad considerados en el Código civil peruano, o sea el error sustancial, el dolo, la violencia y la intimidación, si bien aplicados a la contratación pueden dar lugar a vicios del consentimiento, no son los únicos vicios, y diría yo. ni siquiera son los vicios, que dan lugar a la existencia de la lesión en los contratos.

En efecto, si el fundamento de la lesión fuera proteger al contratante lesionado por la acción de tales vicios, no habria necesidad de que existiera la institución, pues la protección deseada podría alcanzarse mediante la anulación del contrato, que es la acción que franqueza la ley cuando existe vicios de la voluntad.

Para mi, la lesión es algo distinto. El perjuicio que causa la lesión no es el que proviene de la ignorancia debida al error sustancial o al dolo causante, ni de la impotencia proveniente de la violencia o el temor causado por la intimidación. Es, en mi opinión, el perjuicio que sufre un contratante por su debilidad frente al otro, pero no una debilidad cualquier, sino una debilidad que emana de su situación personal, que rompe esa paridad que debe existir entre los contratantes cuando celebran un contrato de carácter oneroso $(*)$.

(*) Es preciso distinguir la lesión de los otros vicios del consentimiento, como son el error, el dolo y la intimidación con los cuales tiene en común, sin embargo, el existir un factor o elemento que afecta el recto querer del agente.

El error.- Este primer vicio consiste en que la voluntad se forma sobre la falsa apreciación de la realidad, lo que determina que sea esa voluntad viciosamente formada sea materia de la declaración, lo que determina que exista una discrepancia entre la declaración y la verdadera voluntad del agente.

La victima de la lesión, en cambio, conoce perfectamente el acto que ejecuta, coinciden su declaración y su voluntad real, aun cuando ésta se ve influenciada por la situación de necesidad en que el sujeto se en- 
Sabemos que el contrato de derecho privado, por celebrarse entre ciudadanos, supone la necesidad de que exista una paridad juridica, o sea que ambos contratantes estén igualmente tutelados por el ordenamiento jurídico a fin de que puedan contratar con libertad. La tutela de esta paridad la ofrece la ley mediante las acciones destinadas a combatir los vicios de la voluntad.

cuentra. La victima de la lesión tiene tal necesidad apremiante de la contraprestación que no vacila en conseguirla aún a riesgo de que su prestación no guarde equivalencia alguna con ella.

El dolo. - Puede ser definido como el error provocado por una conducta maliciosa ajena. Hay dolo cuando con palabras o maquinaciones insidiosas se induce a emitir una declaración de voluntad que sin ellas no se hubiese emitido (ALBALADEJO).

Slendo la consecuencia del dolo el error en que incurre el agente por haber sido engañado, no puede confundirse con la lesión desde que, como se acaba de ver, en ésta el agente tiene pleno conocimiento de lo que hace.

La intimación. - Hay intimación, dice el artículo 1090 del Código civil de 1396, cuando se inspira al agente el fundado temor de sufrir un mal inminente y grave en su persona o bienes, o en la persona 0 bienes de su cónyuge, ascendientes o descendientes.

Si bien existe cierta similitud entre la intimidación y la lesión subjetiva, pues en ambas existe conocimiento del acto $y$ conciencia de realizarlo, en la intimidación la voluntad del sujeto está viciada debido al temor que le ha provocado otra persona, mientras que en la lesión subjetiva la situación que lleva al sujeto a necesitar apremiantemente la contraprestación a cargo de la otra parte no se origina en un hecho de ésta sino que se debe a circunstancias externas al contrato.

A todo lo dicho respecto del error, del dolo y de la intimidación hay que agregar que en estos vicios de la voluntad no hay necesidad de acreditar la existencia de un perjuicio patrimonial, mientras que en la lesión debe presentarse el elemento objetivo de la desproporción entre la prestación y la contraprestación que determina un perjuicio para el sujeto.

La violencia. - No se ha considerado a la violencia (vis absoluta) entre los vicios de la voluntad por cuanto ella tiene carácter físico y constituye en el empleo de una fuerza irresistible que obliga a la victima a bacer algo.

La violencia fisica excluye necesariamente la posibilidad de que exista no solamente la voluntad de declarar sino también la voluntad interna, por lo cual no cabe, en este caso, admitir la existencia de un acto juridico. 
Pero al lado de la paridad jurídica, existe la paridad económica que, como dice MESSINEO $\left({ }^{*}\right)$, significa que cada uno de los contratantes está en condición de sufrir la presión psíquica del otro. PUIG BRUTAU (**) cita una sentencia del Tribunal inglés de la Cancilleria, dictada en 1762, cuyas palabras son las siguientes: "los hombres menesterosos no son verdaderamente libres, sino que para atender a su necesidad apremiante se someterán a cualesquiera condiciones que los poderosos les impongan. ACUÑA ANZORENA $\left({ }^{* * *}\right)$ dice, por su parte, que el estado de necesidad es una causa excluyente del consentimiento por carecer el sujeto de libertad.

En la medida que esa paridad económica no exista; siempre que un contratante pueda imponer al otro condiciones exorbitantes en un contrato por razón de la situación de necesidad de éste, existiria entre los contratantes una disparidad que permitirá a uno de ellos estar inerme, o al menos poco defendido, frente al otro $\left({ }^{*}\right)$.

Sin embargo, como hemos visto, no basta para que se produzca lesión que exista desproporción entre las prestaciones a cargo de cada una de las partes y que tal desproporción haya sido aceptada por el lesionado debido a su necesidad, sino que es necesario, además, que el lesionante, conociendo esa necesidad, abusó de ella para conseguir la celebración del contrato.

Para impedir las consecuencias lesivas del abuso o la explotación de esa situación de necesidad, considero que la acción por

(*) Francesco MESSINEO, Doctrina general del contrato, Buenos Aires, 1952, Tomo I, pág. 52.

(**) José PUIG BRUTAU, Fundamentos de Derecho civil, Barcelona, 1954 Tomo II, Vol. I, pág. 44.

(***) Arturo ACUNA ANZORENA, Notas a Raymundo SALVAT, Tratado de Derecho civil argentino, Buenos Aires, 1950. Tomo I, pág. 89.

(*) Ernesto LA ORDEN, El estado de necesidad en el Derecho privado, pág. 17) define la necesidad como "una urgencia extraordinaria, una premura psicológica, tan estrecha que disminuye angustiosamente el número de los elegibles hasta reducir la elección a una simple alternativa. La voluntad aún puede elegir, pero su elección es $\tan$ misera, es tan necesitada, que no puede menos de constituir un problema la determinación que debe atribuirsele". 
lesión en la concepción subjetiva es el medio adecuado que brinda la ley.

Por lo tanto, cabe llegar a la conclusión que el fundamento de la acción por lesión debe encontrarse en un nuevo vicio del consentimiento de uno de los contratantes derivado de su situación de necsidad, que lo lleva a admitir que es considerado como oneroso un contrato que, en realidad, no lo es. Se trata, por lo tanto, de un fundamento de carácter subjetivo.

Empero, el criterio objetivo no debe ser totalmente descartado, ya que si bien el desequilibrio de las prestaciones no es fundamento suficiente para la acción por lesión, el criterio objetivo puede proporcionar elementos muy valiosos para regular la acción por lesión. En efecto, podria establecerse legislativamente que aunque exista situación de necesidad del lesionado y abuso de esa situación por el lesionante, no procede la acción por lesión cuando el desequilibrio entre las prestaciones no llegue a ser evidente; que cuando tal desequilibrio es evidente sin llegar a ser exorbitante, la prueba de la situación de necesidad y del abuso de esa situación corresponde al lesionado; y que cuando el desequilibrio es exorbitante, se presume tanto la situación de necesidad como el abuso de ella, correspondiendo al lesionante acreditar lo contrario.

Estas consideraciones me llevan a sugerir que la lesión sea admitida en el ordenamiento legal peruano siguiendo un criterio objetivo-subjetivo.

En cuanto a los contratos en que debe admitirse la lesión, si se toma en consideración que tanto la existencia de un vicio del consentimiento, que es el fundamento del criterio subjetivo, como el desequilibrio entre las prestaciones, que es el fundamento del criterio objetivo, son consideraciones aplicables a todos los contratos onerosos, no parece justificado limitar la acción rescisoria al caso del contrato de compraventa y al de partición, como lo hace el Código civil peruano de 1936.

En efecto, si lo que se busca es evitar que una de las partes contratantes sufra un perjuicio por razón del desequilibrio de las 
respectivas prestaciones, esta protección debe darse en todos los casos en que pueda ocurrir tal perjuicio y exista una parte débil que merezca ser protegida.

En la legislación comparada se está marcando la orientación de los Códigos que aceptan la lesión en base a criterios subjetivos en el sentido de admitir que ella es aplicable a todos los contratos onerosos, tal como se verá más adelante.

Diviéndose los contratos onerosos en contratos conmutativos y contratos aleatorios, cabe preguntarse si la acción por lesión debe admitirse sólo en los conmutativos o debe hacerse extensiva también a los aleatorios.

Existe consenso de que, en principio, los contratos aleatorios no son susceptibles de acción por lesión. Los MAZEAUD (*) explican la razón de ello en la siguiente forma:

"Se justifica esa exclusión de la manera siguiente: a causa "del azar, no es posible apreciar si, en el momento del con"trato, las prestaciones eran equivalentes; por otra parte, cuan"do se piden la rescisión o la reducción, el contrato ha sido "cumplido durante un cierto tiempo, el riesgo se encuentra "modificado, de tal suerte que no resulta posible ya volver "a colocar a las partes en la situación en que se encontraban "al concertar el contrato; finalmente, las partes han aceptado "voluntariamente el riesgo, la sumisión al azar, que constitu"ye uno de los elementos del contrato".

Sin embargo, los mismos MAZEAUD (*) admiten que el análisis de otros contratos aleatorios debería conducir a someterlos, en cuanto a la lesión, el régimen de los contratos conmutativos. Citan como ejemplo la venta de un inmueble contra una renta vitalicia donde las partes, para fijar el monto de la renta vitalicia, han fijado previamente el precio del inmueble y han considerado este precio como un capital. En realidad, la primera ope-

(*) Henry, Jean y León MAZEAUD, Lecciones de Derecho civil, Buenos Aires, 1962, Parte II, Vol, I, pág. 402.

(*) IBIDEM, pág. 404. 
ración es indudablemente conmutativa, y sólo la segunda es aleatoria, por lo cual no puede estimarse que este caso es una excepción a la regla general de que la lesión sólo opera en los contratos conmutativos.

Pienso que la solución adecuada de este problema es establecer que procede la acción por lesión en los contratos aleatorios cuando la desproporción entre las prestaciones a cargo de cada una de las partes, proveniente del abuso hecho por una de ellas de la necesidad de la otra, no recaiga en lo que es el álea normal del contrato.

Conviene examinar la legislación comparada para conocer cómo ha sido recibida la institución de la lesión en los distintos ordenamientos nacionales. Ya que no es posible, por falta de espacio, examinar en detalle el tenor de cada uno de los Códigos civiles, se va a intentar agrupar los Códigos según acepten o no la acción por lesión y, entre aquellos que la aceptan, distinguir entre los que se inclinan por el criterio objetivo y los que lo hacen por el criterio subjetivo, debiendo poner de relieve que la gran mayoria de los Códigos que aćeptan la lesión subjetiva la consideran aplicable a todos los contratos onerosos.

El cuadro actual de la legislación civil mundial es el siguiente:

\section{CODIGOS CIVILES}

No aceptan Objetiva Subjetiva

Holanda, 1838 Francia, 1804 Alemania, 199 (art. 138)

Brasil, 1917 (art. 1674) Suiza, 1911 (art. 21)

Honduras Chile, 1855 Suecia, 1915 (art. 31)

Guatemala (art. 1888) Austria, 1916 (art. 879)

Costa Rica El Salvador, Noruega, 1918 (art. 31)

Uruguay 1858 (art. 1825) Turquia, 1926 (art. 21)

Haití

Nicaragua, 1866 México, 1928 (art. 17)

(art. 1888) Polonia, 1934 (art. 42)) 
Colombia, 1873 Italia, 1942 (art. 1448)

(art. 1946) Líbano, 1947 (art. 213)

España, 1889 Filipinas, 1949 (art. 1355)

(art. 1074) Proy. Francia, 1949 (art. 18)

Ecuador, 1912 Etiopia, 1960 (art. 1710)

(art. 1855)

Argentina, 1968 (art. 954)

Perú, 1936

Bolivia, 1975 (art. 561)

(art. 1439)

Proy. Brasil, 1979 (art. 155)

Proy. Bélgica, 1979 (art. 1118)

Nota.- Resulta interesante destacar que algunos paises, como Brasil, Argentina, Bélgica y Francia, que originalmente no aceptaron la lesión o la aceptaron con un criterio objetivo, han modificado o están en via de modificar sus legislaciones para incorporar el criterio subjetivo.

Puede observarse que, salvo el Código civil ecuatoriano de 1912 - que por lo demás es una copia casi literal del Código civil chileno de 1855-, los Códigos que admiten la lesión objetiva son del siglo XIX, mientras que los que la legislan con carácter subjetivo son todos del presente siglo, lo cual de por si es muy elocuente para apreciar la evolución de la lesión.

Sabemos que, además de aceptar la lesión en las particiones; el Código civil peruano de 1936 admite la lesión en la compraventa, en la forma prevista en su artículo 1439, que a la letra dice:

"Art. 1439. - Hay lesión, y por causa de ella puede el "vendedor pedir que se rescinda el contrato, si se vendió un "predio rústico o urbano en menos de la mitad de su valor. "Para probar la lesión se estimará el bien por el valor que "tuvo al tiempo de la venta; pero incumbe al juez apreciar "todas las circunstancias del contrato".

Resulta realmente extraño que nuestro Código civil, dictado en el segundo tercio del siglo XX, siga el criterio objetivo adoptado sólo por Códigos del siglo pasado, y que limite la acción por lesión al contrato de compraventa de predios rústicos o urbanos y solamente en favor del vendedor, cuando la inmensa mayoria de los ordenamientos civiles del siglo XX recogen la ins- 
titución de la lesión con criterio subjetivo y aplicable a todos los contratos conmutativos.

Esto es tanto más sorprendente cuanto que en el seno de la Comisión Revisora del Proyecto de Código civil, donde se discutió a fondo el problema de la lesión, primó la opinión de aceptar la acción por lesión y se encomendó a Manuel Augusto OLAECHEA que presentara una fórmula que permitiera contemplar la lesión dentro de la teoria general de los vicios del consentimiento. OLAECHEA cumplió este encargo presentando a la Comisión un texto inspirado en el Código de la colonia italiana de Eritrea, que decía asi:

“Art. . - Si la obligaciones de una de las partes están "fuera de toda proporción con la ventaja que retira del con"trato, o con la prestación de la otra, y según las circunstan"cias hubiere motivo fundado para estimar que su consenti"miento no fue libremente prestado, el Juez puede, a instan"cia de la parte lesionada, anular el contrato.

"La acción de nulidad debe intentarse en el plazo de un "año del dia del contrato.

"Esta acción es inadmisible si el demandado promete una "indemnización adecuada a juicio del juez".

Puede observarse que la fórmula de OLAECHEA sigue el criterio objetivo-subjetivo, se aplica a todos los contratos y beneficia a cualquiera de los contratantes, con lo cual se encontraba a tono con los avances de las legislaciones modernas en ese sentido. No encuentra justificación que la Comisión Revisora, contando con este valioso aporte, decidiera dejarlo de lado y adoptara la fórmula del actual artículo 1439 que, como se acaba de ver, significa alinearse con los Códigos del siglo pasado y desviarse de las corrientes que ya estaban definitivamente aceptadas cuando esta parte del Código se elaboró. Es triste que esto haya ocurrido.

El Proyecto de Código civil elaborado por la Comisión encargada de la reforma del Código civil de 1936 creada por el De- 
creto Supremo No 95 de $1^{\circ}$ de marzo de 1965, ha tomado un derrotero completamente distinto. En su articulo 1470 indica que la sola desproporción evidente que exista entre la prestación y la contraprestación al momento de la celebración del contrato no autoriza su invalidación, pero agrega que si la desproporción evidente resultara del abuso consciente por la parte que se beneficia con ella como consecuencia del estado de necesidad en que se encuentra la otra parte o de su inexperiencia, puede esta última demandar la rescisión del contrato por lesión.

Por otro lado, el mismo Proyecto establece en su articulo 1471 que la acción por lesión sólo procede tratándose de contratos conmutativos y de contratos aleatorios cuando no está en juego el álea propia del contrato.

Además, los articulos 1473 y 1474 disponen que tanto la prueba del perjuicio que cause la lesión como del estado de necesidad o inexperiencia del lesionado corre a cargo de éste, pero cuando exista una desproporción mayor del triple entre el valor de las prestaciones, se presume el abuso consciente por el lesionante del estado de necesidad o inexperiencia del lesionado $y$, por lo tanto, corresponderá al lesionante demostrar lo contrario.

Finalmente, el artículo 1475 señala que la acción por lesión se transformará en acción por reajuste para hacerla cesar, si el demandado ofrece este reajuste al momento de contestar la demanda.

El Proyecto se sitúa así dentro de la concepción objetivosubjetiva de la lesión, la hace aplicable a todos los contratos onerosos y concede la acción a cualquiera de los contratantes, colocándose asi en la línea de los Códigos más avanzados.

Debe destacarse que la Comisión Revisora creada por la Ley $N: 23403$ ha mejorado estas normas del Proyecto, modificándolas en el sentido que tanto en los contratos conmutativos como en los aleatorios cuando no esté en juego el álea propia del contrato, la desproporción menor de las dos quintas partes entre el valor de la prestación y el de la contraprestación, no permite la rescisión del contrato por lesión ni su modificación para hacerla cesar. 
Si la desproporción entre el valor de la prestación y el de la contraprestación fuera superior a las dos quintas partes y resultare de la explotación por la parte contratante que se beneficia con la desproporción, de la necesidad apremiante o de la inexperiencia de la otra parte, puede esta última ejercitar la acción por lesión.

Si la desproporción fuera superior a las dos quintas partes pero inferior a las dos terceras partes, tanto la prueba del perjuicio como de la necesidad apremiante del lesionado corren a cargo de éste, correspondiéndole también acreditar que el lesionante explotó esa necesidad apremiante o inexperiencia.

Por último, si la desproporción fuera igual o superior a las dos terceras partes, se presume la explotación por el lesionante de la necesidad apremiante o de la inexperiencia del lesionado $y$, por lo tanto, corresponderá al lesionante demostrar lo contrario.

Se supera asi la vaga fórmula del artículo 1470 del Proyecto, que habla de la "desproporción evidente" y deja al arbitrio judicial el determinar cuando se produce esta situación, para reemplazarla por la precisa noción de las dos quintas partes, que sirve para separar la desproporción entre las prestaciones menor de dicha relación que no permite la acción por lesión, de la desproporción superior a ella que si la autoriza. En lo demás conserva el sentido del Proyecto de hacer recaer la carga de la prueba bien sea en el lesionado o bien en el lesionante, según la desproporción entre las prestaciones sea inferior o superior a las dos terceras partes.

Se conjugan armoniosamente asi los criterios objetivo y subjetivo de la lesión.

Como tema final de este articulo, quiero referirme al temor que en algunos causa la admisión de la lesión en todos los contratos por considerarse que da lugar a un semillero de juicios, especialmente en los casos de los contratos de trabajo y en los de arrendamiento de inmuebles urbanos. 
Pienso que este temor, que tiene muchos visos de infundado, no debe ser obstáculo suficiente para proscribir la acción por lesión en la forma como ha sido concebida en el Proyecto de Código civil, con la modificación introducida por la Comisión Revisora, por las siguientes razones:

1) En la lesión, la desproporción entre las prestaciones se aprecia sólo en el momento de celebrarse el contrato. Cualquier desproporción sobreviniente no da lugar a la acción por lesión.

No habria lugar, pues, a que, invocando la lesión, se pretendiera pedir la rescisión o revisión de contratos de ejecución continuada o diferida en cuyo proceso de ejecución se presentara un desequilibrio de prestaciones.

2) Se ha visto que cuando la desproporción inicial entre las prestaciones es menor de dos quintos, no hay lesión.

Si la desproporción es superior a los dos quintos pero inferior a los dos tercios, la prueba de la desproporción, de la necesidad $e$ inexperiencia del lesionado y de la explotación de estos estados por el lesionante corren de cuenta del lesionado. La dificultad de esta prueba será un fuerte argumento disuasivo para quienes deseen aventurarse en un juicio por lesión.

Sólo si la desproporción es superior a los dos tercios, la carga de la prueba recae en el lesionante.

La existencia de esta desproporción inicial entre las prestaciones tan chocante, que hacec suponer que se han dado todos los requisitos para la acción por lesión, es razón más que suficiente para facilitar al lesionado pedir la rescisión del contrato.

3) Son relativamente pocos los juicios que se han entablado en nuestro medio para obtener la anulación de los contratos por error, dolo, violencia e intimidación, que son los vicios de la voluntad que contempla el Código civil de 1936, no obstante 
que podrian proporcionar riquisimos fundamentos para impugnar la validez de los contratos de trabajo o de arrendamiento de inmuebles urbanos.

Nada hace suponer que admitir simplemente un nuevo vicio de la voluntad, como es la lesión en su concepción subjetiva, va a cambiar totalmente la situación y se va a producir una proliferación de juicios.

4) La acción por lesión da lugar a la rescisión del contrato. La modificación del contrato por reajuste sólo se da si el demandado ofrece este reajuste al tiempo de contestar la demanda.

Resulta dificil creer que el lesionado, especialmente en el caso de los contratos de trabajo y de arrendamiento de inmuebles urbanos, entable una acción que lo va a conducir a la rescisión de su contrato, puesto que no es probable que en estos casos el lesionante ofrezca el reajuste.

5) Finalmente, si a pesar de todo esto se entable un gran número de juicios por lesión, ello probaria que las situaciones de injusticia en los contratos son tan grandes y que el abuso del poderoso sobre el débil se produce con tanta frecuencia, que bien vale que se administre justicia y se haga cesar el abuso.

No olvidemos que la existencia del Poder Judical obedece a la necesidad de facilitar la administración de justicia y no de dificultarla o impedirla.

Todas estas consideraciones me llevan a hacer mias las siguientes palabras de José Maria MANRESA Y NAVARRO.

"Es pues de esperar que en nuestra futura ordenación, de "acuerdo con esta nueva tendencia, favorecida por el ejem"plo de otros paises y conscientes al fin de nuestra tradi"ción legislativa, se vuelva a la concesión de la ruptura del "contrato, cuando con olvido de la justa reciprocidad que "debe imperar en las prestaciones, aparezca marcado y ma"nifiesto un desnivel sin fundamento ni razón que lo justi"fique". 